\title{
Contesting Animal Experiments through Ethics and Epistemology: In Defense of a Political Critique of Animal Experimentation
}

\author{
Arianna Ferrari \\ Head of Strategy and Content, Futurium gGmbH, Berlin, Germany \\ arianna.ferrari@posteo.de
}

Generally, an animal experiment can be defined as an intervention on an animal, which causes suffering, harm, and distress, for scientific purposes. In this definition, animal experiments differ from more general scientific investigations concerning animals, such as observational studies in the wild in the fields of ethology or conservation, in which animals are involved but may not be harmed. Nowadays, the use of the term vivisection, in the case of animal experiments, is very controversial. This term originally referred to the cutting of living bodies for scientific purposes and has a long conceptual history (Maehle, 1992). In ancient times, it was used for referring to experiments on animals as well as on humans. Only in modern times, it became a colloquial term for all animal experiments and was much used by opponents in the nineteenth century, as the criticism of animal experiments became organized in a political movement (Maehle, 1990). Many opponents to animal experiments, nowadays, use the term deliberately in a political sense, connecting to past animal protection movements (e.g., the international Citizens' Initiative Stop Vivisection, cf. Rippe, 2009). Animal experimenters, on the other hand, oppose the term on the grounds that there is no chirurgical exploration of living animals in experiments (e.g., German Research Foundation, DFG, 2016).

Currently, animals are used in different ways for scientific purposes: they are used in basic research; in education in a variety of biomedical disciplines, including veterinary medicine; as so-called disease models, to mimic different diseases, mostly human ones; as test subjects in different test settings; in veterinary medicine; in behavioral and cognitive ethological studies; as bioreactors to produce fluids or bodily parts which contain therapeutic substances for human beings (i.e., "gene-pharming"); and as sources of cells, tissues, and

(C) ARIANNA FERRARI, 2019 | DOI:10.1163/9789004391192_008 
organs for human transplantation. Although the capturing, handling, transporting, confining, and breeding of animals are relevant parts of the practice of animal experimentation, they are not explicitly indicated in many laws as animal experiments. This constitutes a problem because these practices cause major distress in animals. Furthermore, the act of breeding animals for scientific purposes, which has become unavoidable (with rare exceptions), since it ensures the standardization and reproducibility of experimental results (cf. Ferrari, 2008), must be considered an ethical issue. In the practice of animal experimentation, individuals are materially formed in their identity as experimental living beings. These animals are often born with specific characteristics suited to scientific experiments (see Linzey and Linzey, 2015). The fact that breeding is not classified as an animal experiment affects the perception of the suffering and the number of animals used for research. For example, in experiments that make use of genetically altered animals, many individuals are used for the realization and maintenance of a, so-called, transgenic animal line, and are not counted in the statistics. Furthermore, many transgenic lines are bred in commercial facilities to be ready for use, so that scientists can order them from a catalogue.

This chapter offers a framework for building a convincing critique of animal experimentation. In order to do so, it first explores the framework that justifies animal experiments in the current debate, which relies both on scientific and ethical arguments. It then analyzes the main arguments developed to oppose animal experiments, in terms of epistemic and ethical arguments. Although valuable, these arguments present some pitfalls when considered separately. The chapter concludes that a convincing critique of animal experimentation must be political.

\section{How Is the Practice of Animal Experiments Currently Justified?}

Although animal experiments are carried out all over the world, in most cases their use is not mandatory. Their main goal is to protect human beings, though protecting non-human animal health and the environment are also goals. This chapter presents the argument that the obligation to perform animal experiments comes from a commonly accepted experimental culture, which is justified on the basis of ethical and epistemic arguments relating to human gains. In the writings which justify animal experiments, often the need to protect human safety is of primary concern. The apparent unavoidability of animal experiments is explained, first through reference to historical arguments and, 
second, through the irreducibility of, so-called, in vivo experiments to other methods (e.g., in vitro, in silico, or computer modelling). For example, the Royal Society (2004) has argued that almost every medical achievement in the twentieth century relied on the use of animals in some way. The German Research Foundation (DFG, 2016), in its paper on animal experiments, maintains that even sophisticated computers are unable to model interactions between molecules, cells, tissues, organs, organisms, and the environment. It is argued that animal experiments result from a cost-benefit-analysis, in which the costs for animals have to be balanced with the benefits for the protection of human health and the environment.

The Principles of Humane Experimental Technique (Russell and Burch, 1959) is one of the first documents on the ethical rationale of animal experiments and has become a milestone in the politics of alternative methods. Russell and Burch formed the basis for a new applied science that would improve or substitute the treatment of laboratory animals, while advancing the quality of science in studies that use animals. They claimed that this science must be inspired by the three principles of replacement, reduction, and refinement with regard to the use of animals. It is important to note that Russell and Burch's intent was ethical, but their methods were descriptive and empirical, not normative. Russell and Burch were inspired by the goal, stated by the Universities Federation for Animal Welfare (UFAW) in the United Kingdom, to promote, socalled, humane behavior, consisting of reducing pain and fear inflicted upon animals (Tannenbaum and Bennett, 2015). The method of replacing, reducing, or refining the use of animals in studies was defined as an empirical approach. According to this method, inhumanity was associated with physical or psychological distress, unnecessary or avoidable pain, fear, stress, anxiety, and bodily discomfort. However, for Russell and Burch, the goal of lessening distress (inhumanity) in scientific procedures was always subordinate to the goals of conducting science and achieving scientific and medical progress. Russell and Burch, indeed, were not criticizing the use of animals in research as such, but promoted methods to reduce and, whenever possible, eliminate animal distress consistent with the conduct of sound science. Although the concept of alternatives was not present in their 1959 book, the ${ }_{3} R s$ have been the foundation for the development of alternative methods, which were formally introduced by Smyth (1978) in Alternatives to Animal Experiments (see Tannenbaum and Bennet, 2015). Smyth defined an alternative as any change in experimental methods that results in the application of the ${ }_{3}$ Rs. Since then, there has been an ongoing debate on the different definitions of these principles and how to apply them to scientific procedures (see e.g., Tannenbaum and Bennett, 2015); but the core of the message remains in favor of animal experiments. Indeed, 
more recently, Russell described the word alternative as "unfortunate" because it suggests only $1 \mathrm{R}$ (Russell, 2005).

The justification of animal experiments has been explained in the clearest and strongest manner in the case of biomedical research. One of the most quoted documents is the Nuremberg Code, which followed the Nuremberg Trials after World War II. The Nuremberg Code states that, "The experiment should be so designed and based on the results of animal experimentation and a knowledge of the natural history of the disease or other problem under study that the anticipated results will justify the performance of the experiment" (Shuster, 1997, p. 1436). Another widely used document is the Declaration of the World Medical Association on the Ethical Principles for Medical Research Involving Human Subjects, first formulated in Helsinki in 1964 (World Medical Association, 1964). This Declaration was formulated as a response to the monstrous threats to humanity during World War II, and it defined the role of animal experiments prior to human exposure: "Medical research involving human subjects must conform to generally accepted scientific principles, be based on a thorough knowledge of the scientific literature, other relevant sources of information, and adequate laboratory and, as appropriate, animal experimentation. The welfare of animals used for research must be respected". Now known as the Helsinki Declaration, it establishes the ethical obligation to carry out animal experiments when results from these experiments are necessary and unavoidable at a given time by the scientific community.

In 2010, inspired by the Helsinki Declaration, which changed the landscape of human experimentation, a group of scientists (approximately 4500 individuals, at the time of writing) formulated the Basel Declaration (2010) "to further advance the implementation of ethical principles such as the ${ }_{3}$ Rs whenever animals are being used and to call for more trust, transparency and communication on the sensitive topic of animals in research". The Basel Declaration states the necessity of animal experiments to meet fundamental scientific challenges (such as human and non-human animal diseases and protection of the environment), and that the necessity will remain in the foreseeable future for biomedical research. The first principle of the Basel Declaration is "to respect and protect the animals entrusted to us and not inflict unnecessary pain, suffering, or harm to them by adhering to highest standards of experimental design and animal care". This is very similar in scope and intent to the ${ }_{3} R s$. The principles that follow provide specific care in particular scientific practices, such as the creation and use of genetically modified animals or the use of animals in education (Basel Declaration, 2010). The German Research Foundation (DFG) explains the ethics of animal experimentation through, so-called, 
patho-inclusive ethics, which they define as follows: "It is not only reconcilable with valuing human interests over those of sentient animals but also with the position that other human interests, such as life and health, knowledge gain, and pleasure may justify causing distress to animals. Moreover, this view does not preclude the killing of animals, but it does demand that the killing should not cause fear or suffering, if possible" (DFG, 2016, p. 43).

In these texts, the argument that justifies animal research relies on the ethical obligation of a profession, which considers the performance of animal experiments the best scientific standard. In other words, the standard of accepting and promoting some animal experiments is described as a scientific standard, since animal experiments are considered the epistemically best way to achieve certain goals. In addition, the commitment of maintaining good animal welfare is an ethical concern but always subordinate to that of the best science. However, it is not only the professional obligation of scientists to use the best standards at a given time which justifies animal experiments. The professional obligation is based on a more general framework on human-animal relationships, which is anthropocentric at its core. It is a form of (unqualified) speciesism, i.e., the unjustified disadvantageous treatment or consideration of those who do not belong to, or are not categorized as belonging to, a certain species (or group of species). Richard Frey (2005) refers to this position as guided by the "argument from benefit" that is derived from utilitarianism, which justifies the infliction of pain on animals to serve different goals, and is combined with speciesism, which states that a species belonging (i.e. human) justifies a different ethical treatment. Indeed, in the case of animals, the costbenefit-analysis is accepted; whereas, in the case of humans, it is not: "utilitarianism for animals, Kantianism for people," as Nozick (1974, p. 39) put it. Cohen (1986) offers a similar defense for animal experiments. Contesting the idea of animal rights because animals lack the capacity to make moral claims, Cohen has argued that we have a strong duty to conduct such experiments to alleviate human suffering and extend human lives.

In summary, defense of animal research is derived from a combination of scientific reasons (the best possible standard at a given time), the ethical obligation of scientists as a professional community (to respect the best possible standards), and speciesism. Although the arguments for animal experiments are accepted by many in society, particularly in terms of regulations and experimental practice, arguments against animal experiments have a long history and have been articulated in different texts and campaigns worldwide. The following sections distinguish between two main arguments against animal experimentation, epistemic (also called, epistemic antivivisectionism) and ethical (also called, ethical antivivisectionism). 
At the core of the epistemic critique of animal experiments is the idea that such experiments are bad science. Bad is used as a synonym for inefficient, scientifically wrong, or misleading. This kind of critique has a long history. Between the third and fourth centuries, BCE, the empiric school of the Ancient Greek rejected the study of anatomical and physiological vivisection, due both to its cruelty and the belief that pain and death would distort the normal appearance of internal organs. In more recent times, some animal welfare and animal rights organizations and philosophers have used examples from the history of biomedical experimentation, and retrospective studies on the influence of animal experiments in human medicine, to criticize the practice. The Italian philosopher, Croce (2000), coined the term, scientific antivivisectionism (antivivisezionismo scientifico), as a rejection of the idea of the transferability of results from one species to another. According to this rationale, modern animal models are of limited use and can even be dangerous because the data produced are not easily translatable to humans (Croce, 2000; Gericke and Reinke, 2011; cf. Pappworth, 1968).

For LaFollette and Shanks (1996) and Greek and Greek (2003) the idea of the unavoidability of animal experiments is misleadingly taken as the "gold standard" within the scientific community. At the center of this critique is the deconstruction of the claim that animal experiments in biomedicine are predictive of human conditions. LaFollette and Shanks $(2004 ; 2006)$ provide a critique of the use of animal models based on evolutionary theory. They observe that phylogenetically related animals have different mechanisms to achieve the same biological functions, a phenomenon they call "causal-functional asymmetry". This phenomenon renders cross-species extrapolations as causal explanations impossible. Knowledge of relevant causal differences, i.e., causal dis-analogies (with respect to mechanisms and pathways), which compromise the usefulness of analogical reasoning, is necessary; however, this knowledge is only possible retrospectively, once a property has already been tested on different species. LaFollette and Shanks (1996) argue that the defense of animal experimentation relies on a scientifically misleading interpretation of the epistemic role of animal models in biomedical research. They explain that this defense is a product of Claude Bernard's legacy, which is based on a hypothetical-deductivist method in biomedicine, coupled with a rejection of statistical laws. Bernard assumed that clinical medicine (including epidemiological studies) could never be a genuine science and believed in the interchangeability of species to test clinical hypotheses (LaFollette and Shanks, 1996). 
The argument defending the unavoidability of animal experiments is based on the confusion between what are known as causal-analogic models (CAMs) and hypothetical animal models (HAMs). Historically, some animal experiments were consistent with hypothetical-deductive methods, in that they were useful to gain knowledge. However, in the present day, with scientific and technical advancements in alternative methods, the potential of molecular biology (together with proteomics and genomics, among others), as well as computer models, animal models have become obsolete and poor scientific practice. As a result, scientists who promote animal models are not adhering to good scientific practice, and continued use of animal models may prevent the attainment of human-relevant results. This critique is apparent in the current debate on the promotion of alternative methods within regulatory toxicology. For example, Hartung (2013) has spoken of "toxic ignorance" and the necessity for a paradigm shift in the twenty-first century that moves away from animal use and embraces new non-animal technologies.

The epistemic critique of animal experiments is supported by considerable literature from retrospective studies, which have established the poor clinical value of animal models (Pound et al., 2004). Though beyond the scope of this chapter, this literature reaches a sobering conclusion that, in many cases, animal experiments show poor methodological quality, problems with evaluation, and limitations of false-positive or false-negative results. Furthermore, there is a visible lack of consistency between the results of animal models and clinical trials, as well as a significant lack of transferability of results (Akhtar, 2015; Knight, 2011). This demonstrates the need for a retrospective evaluation and critical appraisal of the benefits of animal experiments to facilitate a paradigm shift towards non-animal and human-relevant approaches.

The ethical critique of animal experiments is derived from reflection on the moral status of animals as sentient beings: animal experiments impose suffering and death, so that the animals' interests are systematically violated. Hence, this practice is not justified, regardless of its "utility". This kind of critique can be traced to the seventeenth and eighteenth centuries, when a rise in movements opposing cruelty to animals occurred, and men of letters in England denounced the brutality of animal experiments and openly opposed the Cartesian view of animals as automata (Maehle, 1990). The ethical critique of animal experiments explicitly denounces speciesism: "There is only 
one serious moral defense of vivisection. That defense proceeds as follows. Human beings are better off because of vivisection. [...] One thing should be immediately obvious. The benefits argument has absolutely no logical bearing on the debate over animal rights. Clearly, all that the benefits argument could possibly show is that vivisection on nonhuman animals benefits human beings. What this argument cannot show is that vivisecting animals for this purpose is morally justified. Whether animals have rights is not a question that can be answered by saying how much vivisection benefits human beings" (Regan, 2004, p. 174).

The ethical critique attacks the cost-benefits of the animal model in two ways: first, the thesis of inviolable animal rights (right to life and prohibition of the infliction of suffering) intrinsically excludes the institutionalization of a cost-benefit calculation (see Donaldson and Kymlicka, 2011). Second, because the ethical critique denounces that in animal experiments two incomparable magnitudes are compared: the direct, intentional, present infliction and killing of animals and the elaboration of methods to reach future anticipated knowledge that can principally serve to protect humans. In other words, a conflict situation is constructed. Such attempts are part of a long-term strategy for the further development of scientific goals (Wolf, 1988), by which (perhaps) the suffering of some persons (or some animals) can be prevented; and they cannot, therefore, be viewed as a conflict of interest. In the institutionalized practice of animal experiments, animals are born to be experimental tools, they are bred for a purpose, and their biological nature is formed through the identity given to them by human use. If we recognize animals as bearers of fundamental rights, we cannot permit the institutionalization of a cost-benefit measure that violates their life and causes them suffering. The practice of animal experimentation is intrinsically unethical as it forges animals' identity, puts them in confinement, restricts their species-specific traits, and kills them.

Both the epistemic and the ethical arguments have a long history in the critique of animal experiments. However, to facilitate a paradigm shift towards ending animal experiments, one must understand the weaknesses of these approaches. The epistemic critique of using animals strikes the scientific justification of animal experiments at its core, because it argues that these methods are simply not the best scientific standards at a given time. The rejection of professional standards is a strong claim because, as previously explained, 
the argument in favor of animal experiments is built on professional ethics, in which ethical obligations are derived from epistemic standards. However, in an anti-speciesist framework, the apparent force of the epistemic argument becomes a weakness. The epistemic critique is often too general and runs the risk of making the same mistake as its opponents. There are cases in which knowledge can be transferred from animals to human beings. Since this critique contests a pro-animal experiment position on an empirical level, it runs the risk of failure in cases that animal models may be valuable. LaFollette and Shanks' (1994) critique of the predictability of animal models is based on biomedical research; however, when applied to the field of basic research, as well as cases of species-specific veterinary medicine, their argument is weaker (LaFollette and Shanks, 1996). The experimental system in basic research centers on discovering new fields and new uses of knowledge. This characteristic, on the one hand, can permit the elaboration of more complex alternative methods that mimic dynamics and biological properties in efficient ways; however, on the other hand, it also leads to the establishment of new fields and new uses attached to animals.

The second problem with the epistemic critique to animal experiments is that the rejection of speciesism appears to be subordinate to the argument of utility. The epistemic critique is directed towards the benefit side of the costbenefit-analysis but not the analysis in itself. The largest part of intended benefits is human gain. As previously discussed, the protection of human health is the highest priority in the justification of animal use. Therefore, when discussing animal experiments with a rationale, it is close to impossible to reject them. It is important to note that scientists often acknowledge the limitations of their work and express rather modest claims in terms of the applicability of the outcomes of their studies. Nevertheless, they maintain that animal use is necessary and important.

The ethical critique of animal experiments offers a strong case against animal experiments, because it refuses to use a cost-benefit model, which prioritizes human gains. However, the ethical critique is, at times, accused of not explicitly addressing the potential loss of knowledge from renouncing animal experiments. This is apparent in the accelerated development of non-animal alternatives since the European ban on cosmetic testing on animals: "Past experience demonstrates clearly that animal testing provisions in the cosmetics legislation have been a key accelerator in relation to the development of alternative methods and have sent a strong signal far beyond the cosmetics sector and far beyond Europe" (European Commission, 2013, p. 6). The human spirit is creative and to renounce particular strategies encourages other pathways of discovering and working. 
Why are animal experiments considered by some as fundamental and important even though they have limitations? It is impossible to answer this question with reference to empirical results alone. This question is more relevant to values and social goals. The praxis of animal research, of each kind of experimental practice, is a practice in a given time and space in society, and it is a reflection of epistemic and ethical values. Scientific practices are not free of ethical values because: (1) they use limited cognitive and financial resources (and thus it is always a matter of choice in which direction these resources should go); and (2) research activities reflect our values; that is, what we are willing to do in a society, what we consider as an acceptable means to reach an end. When we accept the infliction of pain on and killing of sentient beings, we embrace these values as a society. This is apparent in the justification framework of the Declaration of Helsinki. Since the carrying out of animal research is a matter of a professional ethics (despite the possibility of adjustments if, for example, the experiments are not designed properly), once these experiments meet current scientific standards, it is more difficult to criticize them. Therefore, as long as the infliction of harm on animals is justified, as long as animals are ontologically thought of as "research tools", animal use continues. Thus, overconfidence in animal experiments as scientific techniques is profoundly linked with an instrumental view of animals and life in general.

The fundamental decision on the acceptability of the infliction of suffering and the killing of animals is a reflection of a social order and, of course, not solely a matter of empirical evidence. As a result, the necessity or inevitability of a scientific experiment is always a product of decisions and negotiations in a society. In the case of human clinical trials, there are also considerations of possible benefits and costs (in term of risks for the patient); but the situation is fundamentally different because the life and well-being of human beings is considered more significant than those of animals. For example, in the ethical literature about human clinical trials, the language used to contest some experiments is fundamentally different, and it often refers to vulnerabilities and possible abuses of particular populations and groups. The vulnerability of animals, in contrast, is simply taken for granted in the experimental system. Inasmuch as the idea of human exceptionalism is a political idea (ideology), the possibility of strictly distinguishing epistemic reasons from ethical reasons permits a division of moral labor (e.g., "I conduct science and do not engage with ethical problems, it is not in my field of expertise"), which is highly problematic and, therefore, rejected for human clinical trials. 
The dispute on animal experiments cannot be a dispute on (objective) benefits; it is a dispute on what we as a society want to justify as practices and how we treat the living beings who are a part of it. Science and its practices are a social project. Can humankind benefit from animal abuse? This fundamental political nature of the category of necessity calls for a political critique of animal experiments, a critique that combines both the ethical and the epistemic critical arguments, acknowledging the non-neutrality of scientific decisions. An ethical critique to animal use is weaker, if it is not combined with a critique of the system of experimentation, i.e. the epistemic culture of animal experiments. At the same time, the epistemic critique should free itself from the reference to the category of utility as if it were solely a matter of scientific evidence; resulting in an impasse in front of scientific papers which recognize the limitations of animal models and their perceived importance at the same time, depending on the mechanisms investigated. As previously noted, the choice of renouncing animal experiments in favor of non-animal methods is fundamentally a political choice; this choice should be accompanied by the development of infrastructures and programs to serve as incentives for scientific advancement, and by a new ethos of the scientific community. While these needs have been previously recognized by authors defining animal use as poor science (e.g., LaFollette and Shanks, 1996; Greek and Greek, 2003), it is also important to recognize the political nature of the category of necessity in the experimental practice.

A political critique of animal use strives to substitute the epistemic and ethical culture of animal experiments with a culture of compassion and solidarity, independent of the species-belonging. A political critique of animal experimentation rejects the fundamental subjugation of animal interests "just because they are animals" and openly argues for the establishment of a different ethical culture. In order to be effective, the political critique must admit that it is necessary to give up certain pathways to knowledge while, at the same time, establishing a system in which it is possible to research and develop technologies without violating the fundamental interests and rights of animals.

\section{References}

Akhtar, A. (2015). The Flaws and Human Harms of Animal Experimentation. Cambridge Quarterly Healthcare Ethics, 24(4), pp. 407-419.

Basel Declaration (2010). Basel Declaration. [online] Available at: http://www.baseldeclaration.org/basel-declaration/ [Accessed 11 August 2018]. 
Cohen, C. (1986). The Case for the Use of Animals in Biomedical Research. New England Journal of Medicine, 315(14), pp. 865-870.

Croce, P. (2000). Vivisezione o scienza. La sperimentazione sull'uomo (orig. Aus. 1982). Bologna: Calderini.

DFG (2016). Animal experimentation in Research, Bonn. [online] Available at: http://www.dfg.de/download/pdf/dfg_im_profil/geschaeftsstelle/publikationen/ tierversuche_forschung_en.pdf [Accessed 30 July 2018].

Donaldson, S. and W. Kymlicka (2011). Zoopolis. A political theory of animal rights. Oxford, uk: Oxford University Press.

European Commission (2013). Communication from the commission to the European Parliament and the council on the animal testing and marketing ban and on the state of play in relation to alternative methods in the field of cosmetics. Brussels 11.3.2013. $\operatorname{COM(2013)} 135$ final. [online] Available at: https://eur-lex.europa.eu/ legal-content/EN/TXT/PDF/?uri=CELEX:52013DCo135\&from=GA [Accessed 30 July 2018].

Ferrari, A. (2008). Genmaus \& Co. Gentechnisch veränderte Tiere in der Biomedizin. Erlangen: Harald Fischer.

Frey, R.G. (2005). Animals and their medical use. In: A.I. Cohen and C.H. Wellman, eds., Contemporary Debates in Applied Ethics. Oxford, uk: Wiley-Blackwell.

Gericke, C. and A. Reinke (2011). Was Sie schon immer über Tierversuche wissen wollten: Daten und Fakten. Göttingen: Echo Verlag.

Greek, C.R. and J.S. Greek (2003). Specious Science: How Genetics and Evolution Reveal Why Medical Research on Animals Harms Humans. New York: Continuum.

Hartung, T. (2013). From Alternative Methods to a New Regulatory Toxicology. Alternatives to Animal Experimentation Proceedings, 2(1), pp. 21-25.

Institute for Laboratory Animal Research (2004). Science, medicine, and animals. Washington DC: National Academies Press.

Knight, A. (2011). The costs and benefits of animal experiments. Singapore: Palgrave.

LaFollette, H. and N. Shanks (1994). Animal Experimentation: The Legacy of Claude Bernard. International Studies in the Philosophy of Science, pp. 195-210.

LaFollette, H. and N. Shanks (1996). Brute science. Dilemmas of animal experimentation. New York: Routledge.

Linzey, A. and C. Linzey (2015). Normalizing the Unthinkable: The Ethics of Using Animals in Research. Oxford: Working Group of the Oxford Center for Animal Ethics.

Maehle, A.J. (1990). Literary Responses to Animal Experimentation in Seventeenth and Eighteenth Century Britain. Medical History, 34, pp. 27-51. [online] Available at: https://www.ncbi.nlm.nih.gov/pmc/articles/PMC1035999/pdf/medhistooo56-0031 .pdf [Accessed 30 July 2018].

Maehle, A.H. (1992). Kritik und Verteidigung des Tierversuchs. Die Anfänge der Diskussion im 17. und 18. Jahrhundert. Stuttgart: Franz Steiner. 
Nozick, R. (1974). Anarchy, State, and Utopia. New York: Basic Books.

Pappworth, M.H. (1968). Menschen als Versuchskaninchen. Experiment und Gewissen. Zürich: Verlag Albert Müller.

Pound, P., S Ebrahim. P. Sandercock, M.B. Bracken and I. Roberts, Reviewing Animal Trials Systematically (RATS) Group (2004). Where Is the Evidence that Animal Research Benefits Humans. British Medical Journal, 328, pp. 514-517.

Regan, T. (2004). Empty Cages: Facing the Challenge of Animal Rights. New York: Rowman \& Littlefield Publishers.

Rippe, K.P. (2009). Die Geburt der klinischen Forschung und der Zerfall der ärztlichen Ethik. In: A. Thurneysen, ed., Kontraste in der Medizin. Bern: Lang Peter Verlag, pp. $21-50$.

Royal Society (2004). The use of non-human animals in research: a guide for scientists. [online] Available at: https://royalsociety.org/ /media/Royal_Society_Content/ policy/publications/2004/9726.pdf. [Accessed 30 July 2018].

Russell, W.M.S. (2005). The 3 Rs: past, present, and future. Animal Welfare, 14, pp. 279-286.

Russell, W.M.S. and R.L. Burch (1959). The Principles of Humane Experimental Technique. London, Uk: Methuen. [online] Available at: http://altweb.jhsph.edu/pubs/ books/humane_exp/het-toc [Accessed 30 July 2018].

Shuster, E. (1997). Fifty Years Later: The Significance of the Nuremberg Code. New England Journal of Medicine, 337(20), pp. 1436-1440.

Smyth, D.H. (1978). Alternatives to Animal Experiments. London, UK: Scolar Press.

Tannenbaum, J. and B.T. Bennett (2015). Russell and Burch's ${ }_{3}$ Rs Then and Now: The Need for Clarity in Definition and Purpose. Journal of the American Association for Laboratory Animal Science, 54(2), pp. 120-132.

Wolf, U. (1988). Haben wir moralische Verpflichtungen gegen Tiere?. Zeitschrift für Philosophische Forschung, 42(2), pp. 222-246.

World Medical Association (1964). Declaration of Helsinki-Ethical Principles for Medical Research Involving Human Subjects. Adopted by the 18th World Medical Association General Assembly, Helsinki, Finland. [online] Available at: https://www.wma .net/policies-post/wma-declaration-of-helsinki-ethical-principles-for-medical -research-involving-human-subjects/ [Accessed 30 July 2018]. 